\title{
Low-suction water retention capacity of bentonite at high temperature
}

\author{
María Victoria Villar, ${ }^{1, *}$, Carlos Gutiérrez-Álvarez ${ }^{1}$, and Pedro Luis Martín ${ }^{1}$ \\ ${ }^{1}$ CIEMAT, Avd. Complutense 40, 28040 Madrid, Spain
}

\begin{abstract}
The study of the hydro-mechanical properties of compacted bentonite is relevant in the context of deep geological radioactive waste repositories, where bentonite will be used as buffer material between the waste canisters and the host rock and will be subjected to high temperatures and hydraulic gradients. This research aimed at determining the water retention curves of bentonite compacted at a repositorysignificant dry density $\left(1.6 \mathrm{~g} / \mathrm{cm}^{3}\right)$ and at high temperatures (up to $100^{\circ} \mathrm{C}$ ). This had been previously undertaken, but below suctions around $10 \mathrm{MPa}$ the accurateness of the curves obtained was very low because of the methods and instruments used to determine them. To overcome this uncertainty, thermocouple psychrometers, which work properly in the low-suction range (below $\sim 6 \mathrm{MPa}$ ), were tested. However, calibration showed that their performance was compromised when temperature rose above $60^{\circ} \mathrm{C}$. Nevertheless, the results obtained were consistent with previous ones and allowed to confirm the decrease of water retention capacity with temperature. Additionally, it was checked that this decrease was more important for the low suctions.
\end{abstract}

\section{Introduction}

The use of highly-compacted bentonite as buffer material in radioactive waste repositories prompted the studies of its behaviour under unsaturated state and high temperatures. In most repository concepts the bentonite will be installed in an unsaturated state. Hence, it will be hydrated with the water coming from the host rock at the same time that it will be subjected to a thermal gradient because of the high temperatures generated by the wastes on their radioactive decay. Most repository concepts consider that the temperature at the surface of the canisters should be below $100^{\circ} \mathrm{C}$. However, the nuclear waste management agencies have realised that being able to tolerate higher temperature, whilst still ensuring an appropriate performance, would have significant advantages (e.g. shorter above-ground cooling times, more efficient packaging, fewer disposal containers, fewer transport operations, smaller facility footprints, etc.). In this framework, the European project EURAD, includes a work package devoted to the "Influence of Temperature on Clay-based Material Behaviour" (HITEC), which evaluates whether or not elevated temperature limits (of $100-150^{\circ} \mathrm{C}$ ) are feasible for a variety of geological disposal concepts and aims to determine where the buffer safety functions start to be unacceptably impaired. As a consequence, the determination of hydro-mechanical properties of the bentonite at high temperatures has been undertaken. This will allow properly introducing in the constitutive models the dependence of these properties on temperature. In particular, the precise knowledge of the water retention curve (WRC) -which relates suction to water content (or degree of saturation) - is necessary for the right prediction of the permeability and saturation time of the barrier.

The WRC of the MX-80 and the FEBEX bentonites compacted at dry densities between 1.3 and $1.8 \mathrm{~g} / \mathrm{cm}^{3}$ was determined for a range of temperatures between 20 and $120^{\circ} \mathrm{C}[1,2]$. To perform these determinations two methods were used, both involving total suction. Namely, the vapour transfer technique to equilibrate the bentonite under different suctions, and the measurement of suction of samples with different water contents. The first one is extremely time-consuming, whereas the second one, much quicker, did not allow the testing of very low suctions, because the accuracy of the capacitive sensors used was not good for suctions below $15 \mathrm{MPa}$ ( $\mathrm{RH}>90 \%)$. The present research intended to cover that low-suction range by using also psychrometers, which had been tested by Villar et al. [3] at room temperature. This suction range is relevant in the final stages of saturation of the engineered barrier in radioactive waste repositories, when the bentonite will be close to saturation but the temperature near the waste canisters will still be high.

\section{Background}

In addition to capillary forces, adsorptive forces also affect the pore water and lead to a liquid water film on a hydrophilic surface. The water potential can be represented as the sum of two components (assuming no other contributions), the adsorptive component and the 
capillary component. It is generally considered that although water adsorption processes, i.e. the physicochemical interactions between the clay particles and the water tightly attached to them, dominate in the high suction range, in the zone of low suctions the main mechanism of water retention in compacted samples is capillarity [4]. Hence, soil suction can be assumed in this suction range to coincide with capillary pressure and consequently be ruled by the pore size (taking the soil as a bundle of capillary tubes) according to the Laplace equation. Consequently, interparticle pore size distribution and surface water films are important parameters conditioning the water retention capacity [5]. Additionally, for the high degrees of saturation the effect of the higher density of adsorbed water becomes significant [6].

Jacinto et al. [7] summarised some of the studies carried out on the effect of temperature on the WRC of soils. It is usually considered that the only parameter affected by temperature in this equation is the surface tension of water [8]. Since this decreases with temperature, suction should also decrease with temperature. This has been experimentally confirmed for different soils and granular materials, although generally the temperature effects were larger than those defined by the dependence of water surface tension on temperature. Other factors that may condition the effect of temperature on the capillary component of suction are the changes in clay fabric and pore-water chemistry of the clay.

In particular for bentonites, Tang \& Cui [9] determined the WRC of compacted MX-80 bentonite under free volume conditions at temperatures between 20 and $60^{\circ} \mathrm{C}$. They checked that, for a given suction, lower water contents were obtained as temperature increased. Ye et al. [10] reported the effect of temperature on the water retention capacity of highlycompacted confined/unconfined Gaomiaozi (GMZ) bentonite between 20 and $80^{\circ} \mathrm{C}$. They found that the retention capacity decreased as the temperature increased, both under unconfined and confined conditions. Sun et al. [11] conducted tests with the Czech B75 bentonite under a wide range of temperatures $\left(20-80^{\circ} \mathrm{C}\right)$ and initial dry densities $\left(0.6-1.9 \mathrm{~g} / \mathrm{cm}^{3}\right)$, at high total suction (4-400 MPa), without mechanical loads. The results showed a systematic loss of water retention capacity at high temperature, particularly at low suction, irrespective of the initial compaction.

In all the cases mentioned in the previous paragraph, the WRC was determined by imposing suction by means of different solutions generating different relative humidities, i.e. using the vapour transfer technique. Direct measurement of suction can only be accomplished by using tensiometers in the very low suction range (below $100 \mathrm{kPa}$ ). For this reason, in compacted bentonite, where much higher suction values are expected, devices such as psychrometers or hygrometers measuring relative humidity $(\mathrm{RH})$ are normally used. The values of $\mathrm{RH}$ are then converted to total suction (MPa) by taking into account the temperature through the Kelvin's law:

$$
s=\frac{\rho_{w} \times R \times T}{M_{\mathrm{w}}} \ln \left(\frac{\mathrm{RH}}{100}\right)
$$

where $R$ is the universal constant of gases $(8.3143$ $\mathrm{J} / \mathrm{mol} \cdot \mathrm{K}), T$ the absolute temperature, $\rho_{\mathrm{w}}$ the density of water $\left(998 \mathrm{~kg} / \mathrm{m}^{3}\right.$ at $\left.293 \mathrm{~K}\right)$ and $M_{\mathrm{w}}$, the molecular weight of water $(0.018 \mathrm{~kg} / \mathrm{mol})$.

A combination of both techniques was used by Villar \& Gómez-Espina [1,2] to determine the WRC of the MX-80 and the FEBEX bentonites compacted at dry densities between 1.3 and $1.8 \mathrm{~g} / \mathrm{cm}^{3}$ for temperatures between 20 and $120^{\circ} \mathrm{C}$. It was found that the retention capacity of the FEBEX bentonite was higher than that of MX-80, i.e. for a given suction and dry density, the water content of the FEBEX bentonite was higher, although the difference lessened for low suctions. This could be explained by the kind of cations predominant in the montmorillonite interlayer: calcium and magnesium in the case of FEBEX and sodium for MX-80. The effect of dry density on the water retention capacity depended on the range of suction. In both bentonites the retention capacity decreased as temperature increased, and the difference in the retention capacity of the two bentonites turned out to be less important at high temperature. It became also clear that, in the range of suctions explored, capillary is not the main water retention mechanism in bentonite, but the physico-chemical interactions between the clay particles and the water tightly attached to them.

The effect of temperature on the WRC of bentonite/sand mixtures was measured by Arifin et al. [12] in the range $20-80^{\circ} \mathrm{C}$ using three different suction measurement methods (chilled-mirror hygrometer, non warmed-capacitive sensor, and warmed-head capacitive sensors). The three of them measure relative humidity, which is converted into suction as explained above. The error in total suction measurement was attributed to two factors: the inaccuracy of the sensor used and the excessive condensation of the water vapour onto the measuring system as a result of the existence of isothermal non equilibrium between the vapour space, the soil, and the sensor. The authors concluded that, if the inaccuracy of the suction measuring devices is taken into account, the change in total suction due to temperature effect is insignificant.

In addition to the capacitive sensors mentioned above, caged-screen Spanner-type thermocouple psychrometers (TCP) have been used in this work. Likewise, they can measure the soil total suction by measuring the relative humidity in the air phase of the soil pores or the region near the soil. The TCP operate on the basis of temperature difference measurements between a non-evaporating surface (dry bulb) and an evaporating surface (wet bulb). The temperature difference is related to the relative humidity. Spannertype TCPs are wetted by cooling the measuring junction below the dew-point temperature before each measurement, according to the thermoelectric principle based on the Peltier effect. Using Seeback effect and Peltier effect, the TCP can measure the total suction in a soil sample by using the established calibration curve. 
This curve relates the microvolt outputs from the thermocouple and a known total suction [13].

\section{Materials and methods}

The tests consisted in determining the suction of FEBEX bentonite samples compacted at nominal dry density 1.6 $\mathrm{g} / \mathrm{cm}^{3}$ with different water contents. The relative humidity and temperature of the compacted samples were measured with psychrometers or capacitive sensors and these values were converted into suction through Equation 1.

\subsection{Material}

The FEBEX bentonite is a 900-t batch of bentonite that was extracted from the Cortijo de Archidona deposit and processed in 1996 for the FEBEX project. The processing consisted in homogenisation, air-drying and manual removal of volcanic pebbles on site and, at the factory, crumbling, drying in a rotary oven at temperatures between 50 and $60^{\circ} \mathrm{C}$ and sieving through a 5-mm mess.

The montmorillonite content of the FEBEX bentonite

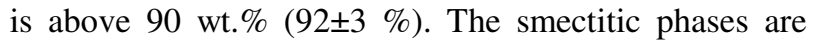
actually made up of a smectite-illite mixed layer, with 10-15 wt.\% of illite layers. Besides, the bentonite contains variable quantities (below 4\%) of quartz, plagioclase, K-felspar, calcite, and cristobalite-trydimite. The cation exchange capacity of the smectite is $102 \pm 4$ meq $/ 100 \mathrm{~g}$, the main exchangeable cations being calcium (35 $\pm 2 \mathrm{meq} / 100 \mathrm{~g})$, magnesium $(31 \pm 3 \mathrm{meq} / 100 \mathrm{~g})$ and sodium $(27 \pm 1 \mathrm{meq} / 100 \mathrm{~g})$.

The liquid limit of the bentonite is $102 \pm 4 \%$, the plastic limit $53 \pm 3 \%$, the density of the solid particles $2.70 \pm 0.04 \mathrm{~g} / \mathrm{cm}^{3}$, and $67 \pm 3 \%$ of particles are smaller than $2 \mu \mathrm{m}$. The hygroscopic water content in equilibrium with the laboratory atmosphere (relative humidity $50 \pm 10$ $\%$, temperature $21 \pm 3{ }^{\circ} \mathrm{C}$, total suction about $100 \mathrm{MPa}$ ) is $13.7 \pm 1.3 \%$. The external specific surface area is $32 \pm 3$ $\mathrm{m}^{2} / \mathrm{g}$ and the total specific surface area is $\sim 725 \mathrm{~m}^{2} / \mathrm{g}$.

\subsection{Methodology}

The bentonite was mixed with different quantities of deionised water. These mixtures were preserved in hermetic plastic bags for several days to ensure a good homogenization. Afterwards, the wet bentonite was compacted inside stainless steel cells at dry density of $1.6 \mathrm{~g} / \mathrm{cm}^{3}$ applying uniaxial pressures between 15 and 69 $\mathrm{MPa}$, higher as the water content was higher. The samples had diameters of $70 \mathrm{~mm}$ and heights of $100 \mathrm{~mm}$. A drill was made in the centre of the top of the cylinders to insert the sensors inside. In some cases two different sensors (capacitive and TCP) were inserted at a time in the same sample. In these cases holes were drilled through top and bottom and each sensor was inserted through a different side. For the capacitive sensors the hole had a diameter of $11 \mathrm{~mm}$ and for the TCPs of $9 \mathrm{~mm}$. Afterwards the lid of the cell was tightened and the hole through which the cable passed through the lid was sealed with thermoresistant silicone. The cell was covered laterally with a silicone heater mat and external insulation was wrapped around (Fig. 1).

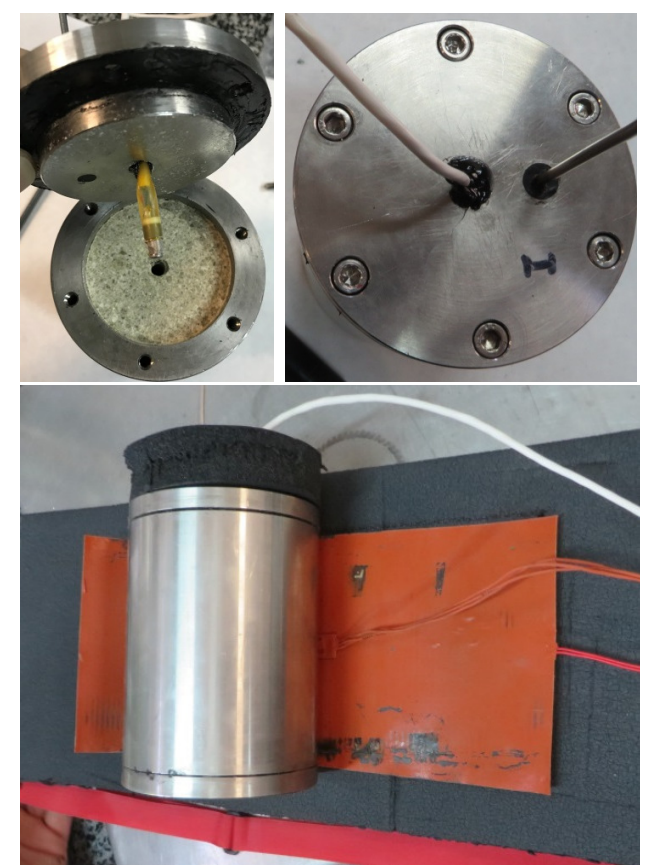

Fig. 1. Cell assemblage: hole drilled on the bentonite surface to insert the sensor, sealing of the cable inlet with thermoresistant silicone, wrapping with heating mat and insulating material.

The tests started at room temperature and the temperature was increased from $40^{\circ} \mathrm{C}$ to $100^{\circ} \mathrm{C}$ at intervals of $20^{\circ} \mathrm{C}$. The characteristic of the samples tested are shown in Table 1 , including dry density $\left(\rho_{\mathrm{d}}\right)$ and water content $(w)$. Since there is no accurate knowledge of the values that the average density of water can take (which would depend on the bentonite density and water content), the customary value of $1 \mathrm{~g} / \mathrm{cm}^{3}$ was used to compute the degree of saturation $\left(S_{\mathrm{r}}\right)$ values shown in the Table. This would partially explain the degrees of saturation higher than $100 \%$ found in some samples $[6,14]$.

Table 1. Characteristics of samples.

\begin{tabular}{|c|c|c|c|c|c|c|}
\hline Reference & $\begin{array}{c}\text { Initial } \\
\boldsymbol{w}(\%)\end{array}$ & $\begin{array}{c}\text { Initial } \rho_{\mathrm{d}} \\
\left(\mathbf{g} / \mathbf{c m}^{\mathbf{3}}\right)\end{array}$ & $\begin{array}{c}\text { Initial } \\
\boldsymbol{S}_{\mathbf{r}}(\%)\end{array}$ & $\begin{array}{c}\text { Final } \\
\boldsymbol{w}(\boldsymbol{\%})\end{array}$ & $\begin{array}{c}\text { Final } \boldsymbol{\rho}_{\mathrm{d}} \\
\left(\mathbf{g} / \mathbf{c m}^{\mathbf{3}}\right)\end{array}$ & $\begin{array}{c}\text { Final } \boldsymbol{S}_{\mathbf{r}} \\
(\%)\end{array}$ \\
\hline $90 \%$ & 22.9 & 1.58 & 87 & 22.8 & 1.60 & 90 \\
\hline $90 \%$ bis $^{\mathrm{a}}$ & 22.9 & 1.50 & 77 & 22.4 & 1.53 & 79 \\
\hline $95 \%$ & 24.5 & 1.57 & 92 & 24.4 & 1.61 & 98 \\
\hline $100 \%$ & 25.4 & 1.61 & 102 & 25.1 & 1.61 & 101 \\
\hline $105 \%$ & 28.9 & 1.57 & 108 & 27.2 & 1.59 & 105 \\
\hline
\end{tabular}

density below the target value 


\subsection{Calibration of sensors and assessment of their performance}

The relative humidity of the samples with higher water content was measured with psychrometers Wescor Elitech PST-55-30-SF with stainless steel filters connected to a Wescor Elitech PSYPRO datalogger. These sensors, $8 \mathrm{~mm}$ in diameter and $30 \mathrm{~mm}$ in length, operate at lab temperature in a suction range from 50 to $6200 \mathrm{kPa}$, with a precision of $\pm 1 \%$ FS. In any case, total suction values between about 300 and $500 \mathrm{kPa}$ should be evaluated very carefully, since this is the range most affected by temperature fluctuation, and below $300 \mathrm{kPa}$ the values could not be valid.

Previous experience with this type of TCPs had shown that the operative range of measurement, for FEBEX bentonite at room temperature, corresponded to samples of water contents higher than $25 \%$ and degrees of saturation higher than 95\% [3, 15]. Trial tests confirmed that the RH of samples with water contents lower than $25 \%$ cannot be measured, because its water potential is lower than the TCP operative range. When the degree of saturation was very high and the temperature was increased, the swelling of the bentonite against the inserted sensor deformed the screen-cage (a stainless-steel protective wire mesh) and could occasion malfunction.

Each TCP is unique and the reliability of the data depends on correct calibration. Prior to use, all the sensors were calibrated at $25^{\circ} \mathrm{C}$ by introducing them in close recipients containing $\mathrm{NaCl}$ solutions of different concentration which generated different RH. The sensor's readings were compared to the theoretical $\mathrm{RH}$ value and a correction factor was applied to every sensor. Accurate sensor calibration and stable temperature environment are key to accurate psychrometric measurements because the sensor outputs are very sensitive to temperature changes or gradients and the temperature differentials and output voltages generated are exceptionally small. When temperature is not stable, measurements take longer and/or are inaccurate.

During the psychrometers' measurement, the sensor tip is cooled for some seconds following the Peltier effect, which makes water condense. Afterwards, evaporation of the condensed water creates a temperature depression of the sample junction in comparison to the dry reference junction. This temperature depression and the resulting voltage output $(\mu \mathrm{V})$ are primarily dependent on the relative humidity inside the sensor, which is converted to water potential (MPa). The measurement of the temperature depression is the difficult part of the process, since this moment is short and difficult to identify. Besides, an equilibrium time is needed before each measurement. After several trials it was possible to fix the time interval for measurement around 60 minutes, and longer if the temperature was high.

The "zero-offset" (null-output in microvolts) of a psychrometer under true isothermal conditions prior to Peltier cooling is zero. This indicates that the net microvoltage outputs of both the reference and the sensing junctions counterbalance each other. It is used to detect the presence and magnitude of temperature gradients. Generally, positive offsets result in water potential estimates that are too dry, whereas negative offsets yield readings that are too wet. For the measurements to be right, it was determined that at room temperature the offset between the two internal thermocouples should be $<3 \mu \mathrm{V}$ (equivalent to $0.05^{\circ} \mathrm{C}$ for chromel-constantan thermocouples). However, for higher temperatures the offset value could be slightly higher and the measurement could still be considered right.

Accuracy of TCPs at the wet end is a limitation of the physics of the psychrometric principle. At water potential around zero $(0 \mathrm{MPa})$, condensation within the sensor is always imminent and the error is significantly greater. The error is dissipated very quickly once a drying force is generated. In addition, hysteresis effects, change of calibration with time and equalisation period are also factors that affect the reliability of the readings [16].

Since the measurements are made in a closed system, the water will evaporate until reaching the saturated vapour pressure in equilibrium with the composition of "free" pore water in the sample at the given temperature (isothermal condition). From this situation, water vapour will move through the material by local concentration gradients and will condense or evaporate, if physically possible, depending on temperature differences. Therefore, the air in the clay pores will be saturated in water vapour $(\sim 100 \% \mathrm{RH})$ at high temperatures close to $100^{\circ} \mathrm{C}$, generating suction values close to zero. The same result could be obtained at temperatures below $100^{\circ} \mathrm{C}$, depending on the properties of the material (water content, pore structure and composition of the pore water). The necessary amount of water to evaporate from the sample is minimal $[14,17]$.

The capacitive transmitters used for the samples with lower water content were Sensirion SHT75. The relative humidity measurement of the capacitive sensors has a precision of $\pm 2 \% \mathrm{RH}$ in the range from 20 to $80 \%$, and between \pm 2 and $\pm 4 \%$ for the other RH values. For the temperature measurement the precision is $\pm 0.3^{\circ} \mathrm{C}$ at $25^{\circ} \mathrm{C}$ and a maximum error of $\pm 1.5^{\circ} \mathrm{C}$ for temperatures of $-40^{\circ} \mathrm{C}$ and $90^{\circ} \mathrm{C}$. These error values have been taken into account when computing the maximum and minimum errors in the suction values obtained with Equation 1.

\section{Results}

Fig. 2 shows the evolution of suction as temperature increased for samples of different degree of saturation. Samples of degree of saturation 90 and $95 \%$ were measured with both sensors. In this range of degree of saturation, the measurements performed with the capacitive sensors showed the usual decrease of suction as temperature increased reported in previous investigations. The accuracy of the measurement clearly worsened as the temperature increased, as a result of the higher uncertainty in the relative humidity measurement 
for the higher values explained in section 3.3. In contrast, the measurements performed in the same samples with the psychrometers were not valid for temperatures below $60^{\circ} \mathrm{C}$. For higher temperatures the psychrometers started to give values that were inside the error interval of the capacitive sensors measurements, but around the limit of the psychrometers' upper range (6 MPa). Maybe for this reason, these values obtained with the psychrometers did not show any clear trend with temperature.

The suction of samples with degree of saturation higher than $100 \%$ could not be measured with the capacitive sensors. For the sample with $S_{\mathrm{r}} 100$ and $105 \%$ suction decreased with the increase of temperature until reaching $0 \mathrm{MPa}$ at $80^{\circ} \mathrm{C}$ in the first case and at $60^{\circ} \mathrm{C}$ for the highest degree of saturation. The increase in temperature triggers the transfer of water from the microstructure to the macrostructure, where it behaves as free water, making $\mathrm{RH}$ to reach $100 \%$ for lower temperatures as the bentonite degree of saturation is higher $[14,17]$.

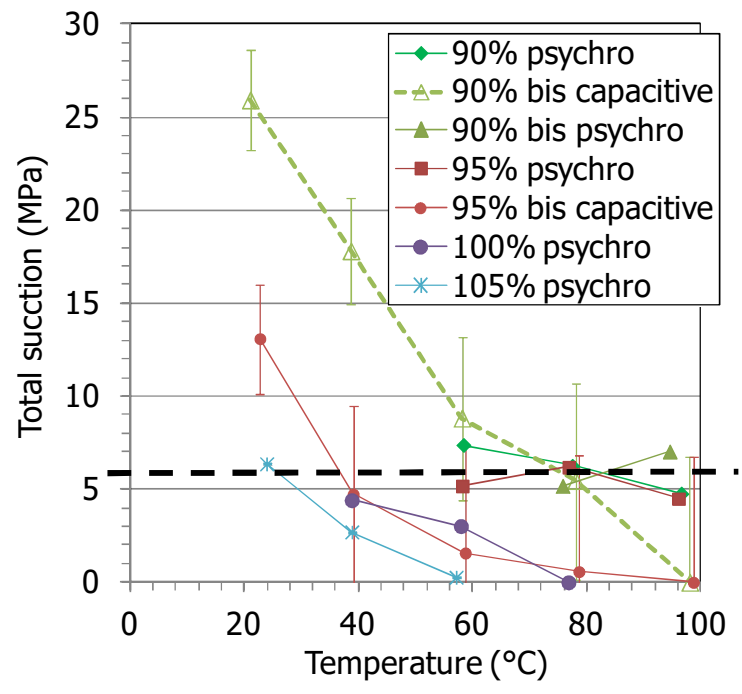

Fig. 2. Change of suction with temperature for FEBEX samples compated at dry density $1.6 \mathrm{~g} / \mathrm{cm}^{3}$ (except sample $90 \%$ bis, see Table 1) with different water contents (the $S_{\mathrm{r}}$ is given in the legend). The dotted horizontal line indicates the upper limit of the measuring range for psychrometers at room temperature.

Fig. 3 shows the results expressed as water retention curves for different temperatures. The lines included are only illustrative of the general trends. The shape of the WRC in the low suction range clearly changes with temperature, the decrease of suction with water content being steeper as the temperature is higher. This is in agreement with the recent work of Sun et al. [11], who were able to interpret their results using a thermodynamically-based model.

These results have been plotted again in Fig. 4 along with results obtained by Villar \& Gómez-Espina [1] for FEBEX bentonite compacted to nominal dry density of $1.6 \mathrm{~g} / \mathrm{cm}^{3}$ but with lower water contents. There is overall a good agreement and a confirmation that the effect of temperature is more significant for the high water contents.

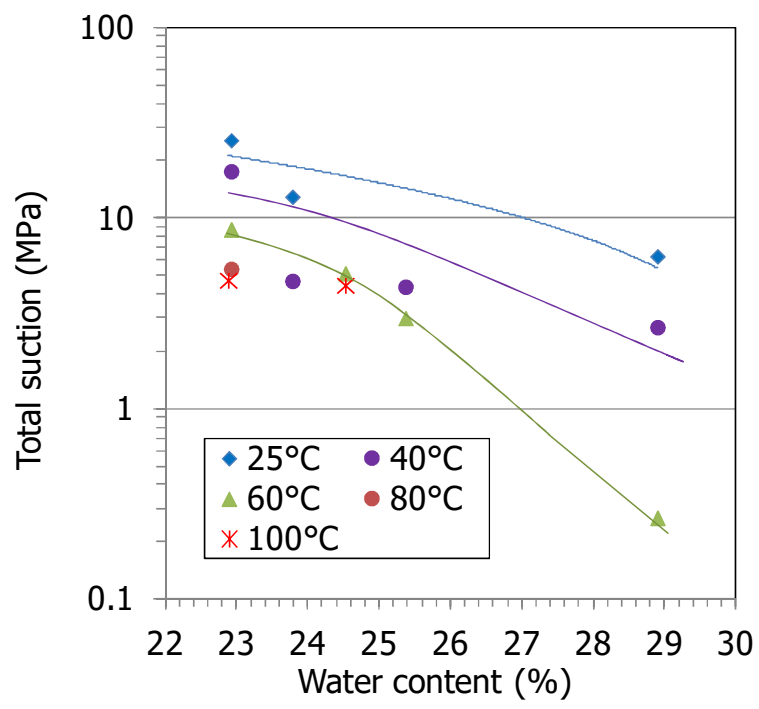

Fig. 3. Water retention curves at different temperatures for FEBEX bentonite compacted at dry density $1.6 \mathrm{~g} / \mathrm{cm}^{3}$.

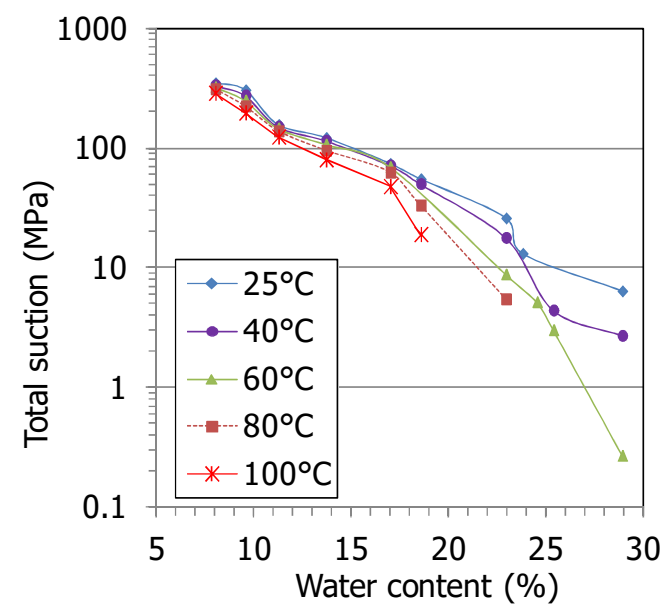

Fig. 4. Water retention curves at different temperatures for FEBEX bentonite compacted at dry density $1.6 \mathrm{~g} / \mathrm{cm}^{3}$ (results from this investigation and Villar \& Gómez-Espina [1]).

\section{Conclusions}

Water retention curves of the compacted FEBEX bentonite under isochoric conditions and temperatures up to $105^{\circ} \mathrm{C}$ were obtained by measuring the relative humidity (RH) of specimens with different water contents, hence, degrees of saturation. In an attempt to obtain a better accuracy in the low-suction range, TCPs were used to measure $\mathrm{RH}$ and temperature along with the customary capacitive sensors, whose accuracy is very low for suctions below $10 \mathrm{MPa}$. Previous calibration showed that the psychrometers did not reach the equilibrium necessary for the measurement for temperatures higher than $60^{\circ} \mathrm{C}$. As expected, they could only be used for bentonite specimens close to full saturation. Nevertheless, both the capacitive sensors and the psychrometers measurements showed the previously 
reported decrease of suction with temperature. The water retention curves obtained at temperatures between 25 and $80^{\circ} \mathrm{C}$ showed a sharper decrease of suction with water content as the temperature was higher.

Future work will be made on calibration of the instruments at a variety of temperatures to assess the relationship between temperature and calibration coefficient for the individual instruments (typical Psychrometer Output: $4.7 \mu \mathrm{V} / \mathrm{MPa}$ at $25^{\circ} \mathrm{C}$ ) and overcome the introduction of unknown potential errors.

\section{Acknowledgements}

This research was performed in the framework of the EURAD project - WP7 HITEC (http://www.ejp-eurad.eu/), which receives funding from the European Union's Horizon 2020 research and innovation programme under grant agreement No 847593. Part of the laboratory work was performed by Juan Aroz at CIEMAT.

\section{References}

1. M.V. Villar, R. Gómez-Espina, In: Experimental Unsaturated Soil Mechanics. Springer Proceedings in Physics 112, 267-274. Springer, Berlin (2007)

2. M.V. Villar, R. Gómez-Espina, Effect of temperature on the water retention capacity of FEBEX and MX-80 bentonites. In: Unsaturated soils: Advances in Geo-engineering. Proceedings of the first European Conference on unsaturated soils, E-UNSAT 2008, 257-262. CRC Press/Balkema. Taylor \& Francis Group, London (2008)

3. M.V. Villar, R.J. Iglesias, C. Gutiérrez, G. Campos, In: Advances in Laboratory Testing and Modelling of Soils and Shales (ATMSS). Springer Series in Geomechanics and Geoengineering, 123-130. Springer, Cham, Switzerland (2017) 10.1007/978-3319-52773-4_13.

4. E. Romero, A. Gens, A. Lloret, Geotech. Geolog. Eng. 19, 311-332 (2001)

5. T. Gimmi, S.V. Churakov, App. Clay Sci. 175, 169183 (2019) 10.1016/j.clay.2019.03.035

6. A. Jacinto, M.V. Villar, A. Ledesma, Géotechnique 62 (8), 657-667 (2012) 10.1680/geot.7.00127

7. A.C Jacinto, M.V. Villar, R. Gómez-Espina,, A. Ledesma, App. Clay Sci. 42, 575-582 (2009) 10.1016/j.clay.2008.04.001

8. J.R. Philip, D.A. de Vries, Trans. Am. Geophys. Union 38 (2), 222-232 (1957)

9. A.-M. Tang, Y.-J. Cui, Can. Geotech. J. 42, 287-296 (2005). 10.1139/t04-082

10. W.M. Ye, M. Wan, B. Chen, Y.G. Chen, Y.J. Cui, J. Wang, J. Central South Univ. Tech. 16, 821-826 (2009) 10.1007/s11771-009-0136-X

11. H. Sun, D. Mašín, J. Najser, G. Scaringi, Eng. Geol. 269, 105549 (2020) 10.1016/j.enggeo.2020.105549

12. Y.F. Arifin, S.S. Agus, T. Schanz. In: Unsaturated Soils 2006. ASCE Geotechnical Special Publication 147, 1314-1325 (2006)
13. X. Tang, J. Graham, A.W.L. Wan. In: Proceedings of the XIV th International Conference on Soil Mechanics and Foundation Engineering 1, 213216. Hamburg (1997)

14. A. Lloret, M.V. Villar, Phys. Chem. Earth Parts $\mathrm{A} / \mathrm{B} / \mathrm{C} \quad 32 \quad(8-14), \quad 701-715 \quad$ (2007) 10.1016/j.pce.2006.03.002

15. M.V. Villar, G. Campos, L. Gutiérrez-Nebot, X. Arroyo, App. Clay Sci. 182, 105290 (2019) 10.1016/j.clay.2019.105290

16. R. Cardoso, E. Romero, A. Lima, A. Ferrari, In: Experimental Unsaturated Soil Mechanics. Springer Proceedings in Physics 112, 79-93. Springer, Berlin (2007) 10.1007/3-540-69873-6_8

17. M.V. Villar, A. Lloret, App. Clay Sci. 26, 337-350 (2004) 10.1016/j.clay.2003.12.026 